Peer Relations, Parental Social Coaching, and Young Adolescent Social Anxiety

Resubmitted Nov 16, 2015 


\begin{abstract}
Links between peer relationship difficulties, parental social coaching, and social anxiety were examined among young adolescents $(N=80)$. In a lab protocol simulating peer stress, adolescents led a 3-min conversation, while ostensibly being evaluated by (fictitious) peer judges. Parental coaching was measured via observed cognitive framing and advice-giving; parents also reported on their facilitation of access to peers, and their adolescent's peer victimization and rejection. Social anxiety was measured through both global- and contextspecific reports. More socially anxious youths (1) experienced more peer rejection and (2) had parents who engaged in poorer quality coaching (i.e., lower prosocial advice, benign interpretation, and facilitation). Evidence of additive effects of peer problems and parenting was found, and the pattern of findings was similar after controlling for adolescent social skills. Results suggest that both negative peer experiences and parental coaching may need to be targeted to reduce social anxiety during early adolescence.
\end{abstract}

Keywords: peer relationship difficulties, social anxiety, parental social coaching, early adolescence 


\section{Peer Relations, Parental Social Coaching, and Young Adolescent Social Anxiety}

Childhood and adolescent social anxiety has received increasing attention in recent years because of its concurrent correlates and long-term consequences, such as loneliness, depression, peer victimization, poor academic and occupational achievement, and avoidance of social activities (Beidel \& Turner, 2007; Kingery, Erdley, Marshall, Whitaker, \& Reuter, 2010; Morris, 2001). Social anxiety refers to feelings of anxious anticipation and distress in social situations as well as intense fears of negative evaluation (Beidel \& Turner, 2007; Leary \& Kowalski, 1997). The prevalence of social anxiety peaks during the early to middle adolescent years, when there is an increased amount of time spent with peers in a diverse array of structured and unstructured activities (Beidel, Turner, \& Morris, 1999; Steinberg \& Morris, 2001; Westenberg, Gullone, Bokhorst, Heyne, \& King, 2007). Further, social novelty increases as young adolescents move into a larger and less familiar school environment in middle school (Duchesne, Ratelle, \& Roy, 2012). Moreover, rates of peer victimization climb around the transition to adolescence and may further contribute to increasing social anxiety. Approximately $10-15 \%$ of young adolescents report at least weekly peer victimization experiences, and 50\% report at least occasional peer victimization (Nansel, Overpeck, Pilla, Ruan, Simons-Morton \& Scheidt, 2001; Wang, Iannotti, \& Nansel, 2009; Williams \& Guerra, 2007). Thus, pressures to manage peer relations and independently cope with increasingly complex peer situations might amplify social fears around the transition to adolescence (Parker, Rubin, Erath, Wojslawowicz, \& Buskirk, 2006).

Although several studies have shown that negative peer experiences are concurrently associated with social anxiety in children and adolescents (e.g., Flanagan, Erath, \& Bierman, 2008), very few studies have investigated whether multiple dimensions of peer relations (e.g., peer rejection, peer victimization) are associated with social anxiety in early adolescence. It is 
important to examine multiple aspects of peer relations simultaneously since it is unclear if these different aspects contribute uniquely to social anxiety (Tillfors, Persson, Willén, \& Burk, 2012). Similarly, two key domains of parental socialization—-parental social coaching about peer problems and parental facilitation of peer contact — have not been examined as independent predictors of social anxiety during early adolescence to our knowledge, despite the fact that peer interactions and peer maltreatment are common sources of social anxiety (Rao, Beidel, Turner, Ammerman, Crosby, \& Sallee, 2007). Studies focused on parenting have mainly examined more general parenting styles (e.g., warmth, controlling) and social anxiety (e.g., McLeod, Wood, \& Weisz, 2007).

The current study is designed to illuminate the role that negative peer experiences and peer-related parenting play in young adolescents' social anxiety. The first aim is to explore whether parent-reported peer victimization and rejection are associated with self-reported social anxiety during a lab-based peer evaluative stress task (context-specific social anxiety), as well as self-reported global social anxiety (i.e., via questionnaires). The second aim is to examine associations linking observed parental coaching (i.e., behavioral advice and cognitive framing about peer evaluation) and parent-reported parental facilitation (e.g., drive your child to parties or activities with other kids) with self-reported global and context-specific social anxiety among young adolescents. The last aim is to test whether negative peer experiences and peer-related parenting serve as additive or redundant predictors of social anxiety. Observed social skill is controlled due to the possibility that lower social skill accounts for associations between social experiences and social anxiety.

Links between Peer Problems and Social Anxiety 
Individual differences in social anxiety during early adolescence may stem from earlier and ongoing interaction experiences with peers. Young adolescents who have generally negative experiences in their peer relationships may develop negative expectations for future social situations that amplify their social anxiety. Two aspects of poor peer relationships that may be particularly germane in the development of social anxiety are peer rejection and peer victimization. Peer rejection generally refers to high levels of disliking and low levels of liking by the peer group (Bukowski, Sippola, Hoza, \& Newcomb, 2000). The experience of peer rejection might undermine feelings of comfort and competence in social situations and limit opportunities for positive social interaction. Research consistent with this premise has shown that higher levels of social anxiety are associated with lower peer acceptance scores for children and adolescents (e.g., Erath, Flanagan, \& Bierman, 2007; La Greca \& Lopez, 1998).

Peer victimization involves exposure to abusive processes and negative treatment by others (Ladd, 1999; Storch \& Ledley, 2005). These experiences might foster feelings of humiliation and exacerbate social fears and avoidance (La Greca \& Harrison, 2005; Storch, Nock, Masia-Warner, \& Barlas, 2003). Evidence of both concurrent and longitudinal relations between peer victimization and social anxiety has been reported. For instance, one crosssectional study found that higher rates of peer victimization were associated with higher levels of social anxiety among high school students (Gren-Landell, Aho, Andersson, \& Svedin, 2011), and findings from a longitudinal study suggest that adolescents' peer victimization predicts an increase in social anxiety over 9 months (Siegel, La Greca, \& Harrison, 2009).

Although peer rejection and peer victimization tend to be correlated, each has been found to make unique contributions to children's and adolescents' developmental outcomes (Ladd, Kochenderfer, \& Coleman, 1997). However, few studies have examined multiple dimensions of 
peer experiences simultaneously as predictors of social anxiety (Flanagan et al., 2008; La Greca

\& Harrison, 2005; Tillfors et al., 2012). Thus, to better understand the impact of peer group experiences on social anxiety, the influence of both dimensions were examined in the present study.

\section{Links between Peer-Related Parenting and Social Anxiety}

As noted by Ladd and Pettit (2002), parental influence on children's and adolescents' social-emotional development can be distinguished in terms of parental style (i.e., the general quality of the parent-child relationship, captured by such concepts as parental responsiveness) and in terms of "direct" (deliberate and intentional) parenting practices. In the domain of socialization of children's peer relationships, a number of different "direct" parenting strategies have been studied, including parents as instructors (McDowell \& Parke, 2009) and as managers (Ladd, Profilet, \& Hart, 1992). Ladd et al. further distinguished aspects of parents' management behavior into four roles: designer, mediator, supervisor, and advisor or consultant. In the early adolescent years, two of these roles - designing (in terms of facilitating access to peers) and advising (in terms of helping teens think through and respond to challenging peer situations; i.e., "social coaching") may be especially salient. Each of these parenting approaches was a focus of the present study.

Parental social coaching. Parental social coaching is defined as parental behavioral guidance or cognitive framing about peer-related challenging situations (e.g., trouble making new friends, difficulty gaining peer acceptance) (Abaied \& Rudolph, 2011; Ladd \& Pettit, 2002; Mize and Pettit, 1997). Parents who engage in effective parental social coaching would confirm adolescents' social competence, support their independent decision-making about social 
challenges, minimize imagined threat, offer prosocial strategies, and communicate warmth and sensitivity to the adolescents' own desires or feelings (Gregson, Erath, Pettit, \& Tu, in press).

During the transition into middle school, social cues between peers are often ambiguous and open to distorted interpretations. Whereas benign and nonthreatening social interpretations are linked with various indices of positive peer relationships (Ladd, 2005), negative interpretations of ambiguous situations are associated with social avoidance and increased social anxiety (e.g., Lau, Pettit, \& Creswell, 2013; Mathews \& MacLeod, 2005). Children may adopt an anxiety-associated processing style through social learning mechanisms, for example, by modeling of parents' style (Reuland \& Teachman, 2014). Thus, parental negative or threatening interpretations in ambiguous situations might amplify adolescents' social fears. Consistent with this premise, Hane and Barrios (2011) found that mothers' expansion of threat-related themes during mother-child discussions about neutral and ambiguous situations was associated with higher anxiety in their 8-10 year-old children.

Explicit instruction or prosocial advice from parents regarding the ways in which children handle problematic social situations also is related to children's social competence and behavior with peers (e.g., McDowell et al., 2003; Mize \& Pettit, 1997; Poulin, Nadeau, \& Scaramella, 2012), and therefore may influence social anxiety. Prosocial behavioral advice instructs an adolescent about friendly behaviors that are sensitive to social and situational cues, and thereby presumably provides concrete ideas for peer interactions, strengthens a sense of social competence, and allays fears about novel peer stress situations (Ladd \& Pettit, 2002). In contrast, parental social coaching that contains vague prosocial or few strategies might be viewed by children as ineffective and unhelpful, potentially undermining self-confidence and increasing social anxiety. 
Parental facilitation. A second way in which parents may directly shape young adolescents' social-emotional development involves regulating children's opportunities for social interactions as a designer (Ladd \& Pettit, 2002), or a provider (McDowell \& Parke, 2009). Parents can do this by choosing or promoting certain contexts for children's peer interaction (Vernberg, Beery, Ewell, \& Absender, 1993), providing children with a wider variety of social interactions and potential friends and opportunities to practice peer interaction skills and build friendships, and thus possibly lower social anxiety. However, empirical evidence is limited due to the lack of research directly examining the link between parental facilitation and social anxiety. Assessing Social Anxiety in Young Adolescents

Several well-known instruments assess anxiety across a range of times and situations, such as the Social Anxiety Scale for Adolescents (SAS-A; LaGreca \& Lopez, 1998). Although feelings of social anxiety are somewhat generalizable, real-time assessments of social anxiety in challenging social situations may be an important complement to global assessments. Social information-processing theory suggests that social information is context-specific, that is, a particular kind of perceived slight or threatening situation sets into motion a chain of cognitive and emotional processes that lead to scripted pattern of interpreting and reacting to such experiences (Petti \& Mize, 2007; Pettit, Polaha, Mize, 2001). For example, Dodge and Somberg (1987) found that aggressive boys displayed cognitive biases and deficits relative to normal boys, especially under conditions of threat. Extrapolating from these findings, situational factors may play important roles in triggering social anxiety. That is, it is possible that the social anxiety level for certain children may be exacerbated under real-time challenging situations, and this 
individual difference in the intensified level of anxiety cannot easily be captured by questionnaires administered under normal, relaxed conditions.

In several clinical sample-based studies, youths subjectively rate their levels of fear or anxiety during social-evaluative tasks (Beidel, Turner, \& Morris, 2000; Ferrell, Beidel, \& Turner, 2004). However, fewer community-based studies have used real-time assessments of social anxiety. The current study will advance the literature by examining whether peer relationship difficulties and parenting strategies are similarly or differently associated with global and real-time, context-specific assessments of social anxiety. We included a widely used global social anxiety measure, in which young adolescents responded to various statements/situations on a questionnaire designed to capture their general social anxiety level. We also recorded young adolescents' self-reported feelings of anxiety during a lab-based peerevaluation challenge.

\section{Research Questions and Hypotheses}

In the present study, associations between negative peer experience and social anxiety were examined. Given the central role of social skills in developmental models of social anxiety (Rubin \& Burgess, 2001) and treatments for social anxiety (Beidel \& Turner, 2007), observed social skills were controlled in analyses to clarify the contributions of peer experiences to social anxiety above and beyond social skills. Based on prior research, we hypothesized that victimized and rejected youth would display more social anxiety, and that these associations would hold after taking into account socio-demographic characteristics and observed social skills. A noteworthy feature of the study is that different informants/methods were used to assess peer problems (parent report), social anxiety (adolescent report), and social skill (direct observation). Although sociometric assessment is the most common and reliable approach used by 
developmental psychologists to study the quality of children's peer relations, parents can provide reliable and valid reports (Bagwell, Molina, Pelham, \& Hoza, 2001; Cole, Maxwell, Dukewich, \& Yosick, 2010; Erath, Tu, El-Sheikh, 2012; Goodman, Meltzer, \& Bailey, 1998). For example, Ladd and Kochenderfer-Ladd (2002) found that parent reports of peer victimization were reliable and stable and moderately correlated with self, teacher, and peer reports, and similarly predictive of other measures of social adjustment. The current study used parent reports of peer problems to avoid common informant variance.

We also anticipated that parental cognitive framing, prosocial advice, and facilitation would be associated with lower levels of social anxiety, net of socio-demographic factors and social skills. The additive (independent) associations between parental coaching, peer problems, and social anxiety were also of interest. No specific hypothesis was advanced because evidence in the literature for the additive (vs. redundant or overlapping) impact of parenting and peers on adolescent psychological distress is mixed, with some studies showing that problems in one domain do not contribute to outcomes above and beyond problems in the other domain (e.g., Fanti \& Henrich, 2010) and other studies providing evidence of cumulative risk (e.g., Criss, Pettit, Bates, Dodge, \& Lapp, 2002; Festa \& Cinsbury, 2011).

\section{Method}

\section{Sample}

A total of 80 young adolescents (at T1, Mage $=11.92$ years, $S D=1.27$ ) and their parents (79\% biological mothers) participated in this study. The sample of young adolescents included 55\% male and 55\% African American, 43\% European American, and 2\% of other races/ethnicities, consistent with demographics of the communities from which participants were 
recruited. The mean family income was between $\$ 20,001$ and $\$ 35,000 ; 24 \%$ reported an income of less than $\$ 20,000$, and $22 \%$ reported an income of more than $\$ 75,000$.

\section{Procedure}

Participants were recruited via flyers posted in community locations and sent home with students in fifth and sixth grade classrooms in public schools in the southeastern United States. Parents who responded to the school flyers were given information about the study, including the lab protocol, and were scheduled for a research visit over the phone. The lab visit lasted approximately 2 hours, and both parents and adolescents were compensated monetarily. Both adolescents and parents completed questionnaires and participated in lab activities. During the lab visit, young adolescents were asked to participate in peer evaluation and parent-adolescent discussion lab activities. The peer evaluation period refers to the conversation activity, in which a research assistant (RA; same-sex) asked the adolescent to lead a three-minute conversation with the RA as if they were meeting for the first time. Young adolescents were told to lead this conversion by telling about themselves, asking questions about the RA, or talking about anything they wanted. They were also told that the conversation would be watched by three same-age, same-sex peer judges (actually fictitious) through one-way Skype. Participants were told that the peer judges would decide how well they performed in the conversation activity compared to two other participants the peer judges had watched on video. The RA then told participants that they may have a chance to try to change the peer judges' opinions by speaking directly to the peer judges through the webcam if they were not chosen by the peer judges as a top performer. Adult RAs participated in the conversation activity to ensure adherence to standardization guidelines (e.g., number of follow-up questions), such that variability in social anxiety levels was driven by individual differences among participants rather than variability in task demands. 
After the peer evaluation period, young adolescents were asked to have a three-minute conversation with their parent about what they should do if they are not selected by the peer judges as a top performer. Prior to the parent-adolescent discussion, parents were also instructed to prepare their child in case s/he was not chosen as one of the best performers. Parents were told that they could approach the conversation with their child in any way they wanted, and example conversation topics were given, including reasons why the child might not be chosen (if not chosen), whether s/he should speak directly to the peer judges to change their minds, and, if so, what s/he should talk about. Following the parent-adolescent discussion, the task was ended and participants were carefully debriefed and led to their own conclusion that the peer judges were fictitious. The rationale for deception and purpose of the study were discussed. After finishing all lab tasks, young adolescents and parents filled out questionnaires. All study procedures were approved by the University Institutional Review Board.

\section{Measures}

An effort was made to ensure methodological/informant independence when possible. Social anxiety measures were drawn from adolescent report, using both a well-validated questionnaire and an in-lab interview. Peer problems were indexed via parent reports, using instruments previously shown to correlate with both child and teacher reports of analogous problems (e.g., Bagwell et al., 2001; Cole et al., 2010; Erath et al., 2012; Goodman et al., 1998; Ladd, \& Kochenderfer-Ladd, 2002). Parental social coaching and socially skillful behavior were rated by observers blind to the measures of social anxiety or peer problems.

\section{Social Anxiety}

Social anxiety was assessed in two ways. At the global (i.e., questionnaire) level, it was assessed with the Social Anxiety Scale for Adolescents (SAS-A; La Greca \& Lopez, 1998), an 
18-item self-report measure (e.g., "I feel that others make fun of me"; "I feel shy even with peers I know very well"), with items rated on a 5-point scale $(1=$ not at all, $5=$ all the time $)$. Averaged scores were used in the present analyses $(\alpha=.93)$. At the context-specific level, anxiety was assessed with a composite of two items from the peer evaluation period. Prior to and following the peer evaluation period (before the parent-adolescent discussion), interviewers asked participants to rate on a 5 -point scale $(1=$ not at all, $5=$ very $m u c h)$ "how anxious are you/were you." The two items were moderately correlated $(r=.52, p<.001)$ and were averaged to create a lab-based, context-specific social anxiety measure.

\section{Peer Problem Predictors}

Peer victimization. Parents completed seven items that are commonly used to assess children's peer victimization experiences (e.g., "My child is picked on by other children”, “Other children try to hurt my child's feelings by excluding him or her"; Ladd \& Kochenderfer-Ladd, 2002; Schwartz, Chang, \& Lee-Shin, 2002), rated on a 5-point scale $(0=$ never true, $4=$ always true). Internal consistency was high $(\alpha=.93)$.

Peer rejection. An index of peer rejection was obtained through a parent-report version of the Checklist of Peer Relations (Coie \& Dodge, 1988). Parents rated 6 items on a 5-point scale (0 = never true, 4 = always true; e.g., "other children actively dislike my child and reject him or her", "Other children like my child and seek him or her out" — reversed score). Averaged scores were used. Internal consistency was high $(\alpha=.83)$.

\section{Peer-Related Parenting Predictors}

Videos (with accompanying transcriptions) of the parent-adolescent problem-solving discussion were independently coded for the parent's social coaching (exclusive of the child's behavior) by two well-trained researchers. Aspects of coaching during the discussion period 
were coded separately on a 5-point scale and used in the present study. Ten percent of the sample $(n=8)$ were coded by the research team as a group; all discrepancies were resolved by consensus. The remaining $90 \%$ were coded by two independent graduate research assistants, who had been trained on the other $10 \%$ of the sample and were required to reach acceptable inter-rater reliability $(\mathrm{ICC}>.75)$.

Cognitive framing. Benign interpretations $(1=$ absence of any benign interpretations, $5=$ multiple, elaborate benign interpretations, often accompanied by positive affect) referred to parents framing the lab activities (peer-evaluation and reconnect plan) in nonthreatening, positive terms, affirming the adolescent's competence in the situation, or reinforcing the adolescent's perception of control over the situation (e.g., "Just think of them like they are your friends at school." "All in all, it's really not a big deal what those kids think of you." "Remember when you were new at school and were so friendly and met all those new kids?”).

Threatening interpretations $(1=$ absence of any threatening interpretations, $5=$ multiple, elaborate threatening interpretations, often accompanied by negative affect) referred to the parent's framing of lab activities in an intimidating, negative manner, suggesting that the adolescent should be concerned, pressuring the adolescent to reconnect, emphasizing negative emotions that the adolescent denied, or undermining the adolescent's confidence (e.g., "Are you sure you're not scared?" "Do you think the other kids did better than you?" "You really don't want to leave things on a bad note-you really should talk to them again.”).

Lastly, socially attuned coaching (1 = disregard for child's feelings, comments, or reconnect plan, 5 = considerate of adolescent's perspective; positive, playful, responsive to adolescent's comments) referred to the parent's considerateness and responsiveness to the adolescent's feelings and perspective about the peer challenge (e.g., "I could understand it would 
be really hard to do this again, but I think you can do it." "You know the decision is totally up to you! I think you'll do a good job no matter what you choose.”).

Inter-rater reliability was high for each of the three categories (ICC for benign interpretations $=.83$; threatening interpretations $=.75$; attunement $=.83$ ). On average, parents displayed a moderate level of benign interpretations $(M=3.01, S D=1.23)$, lower levels of threatening interpretations $(M=2.30, S D=1.36)$, and higher levels of attuned coaching $(M=$ $3.45, S D=1.19)$. To create a composite variable representing positive cognitive framing, the threatening interpretations variable was reverse-scored and the three codes were averaged. Internal consistency of the composite variable was acceptable $(\alpha=.67)$.

Behavioral advice. Prosocial behavioral advice $(1=$ absence of any prosocial advice, $5=$ multiple prosocial topics that can be elaborated) referred to prosocial or friendly advice that the parent gives about reconnecting with the peer judges that is likely to produce a more positive interaction and favorable reaction from the judges. Ratings were based on the prosocial quality and specificity of advice given to the adolescents (e.g., "be friendly/nice"; "find out if you like the same sports and see what their favorite teams are"). On average, parents displayed a low level of prosocial behavioral advice $(M=1.53, S D=1.12)$. The inter-rater reliability was high for prosocial behavioral advice $(\mathrm{ICC}=.83)$.

Parental facilitation. Parents' facilitation of young adolescents' opportunities for positive peer interaction was indexed by five items (Vernberg et al; 1993), rated by parents on a 5-point scale $(0=$ never true, $4=$ almost always true; e.g., "Drive your child to parties or activities with other kids", "Let you child invite friends to sleep over"). The internal consistency was acceptable for the current study $(\alpha=.68)$.

\section{Control Variables: Conversational Skill}


Conversational skills during the peer evaluation task were assessed using observational ratings developed in a previous study (Erath et al., 2007). Participants were rated on seven social skill items, including facial expression, eye contact, voice animation, mood, confidence, social sensitivity, and global conversation skill. Each item was rated on a 5-point scale $(1=$ not at all, 5 = very much) by trained undergraduate and post-graduate coders who were unaware of participants' social anxiety level. Coders were trained on practice tapes until they achieved an inter-rater reliability of .70 on each item. For each coder, a minimum of $25 \%$ of tapes were also rated by a master coder to assess reliability. In total, fifty-five percent of the interactions were reviewed by the master coder, and discrepant ratings were resolved by consensus. Ratings on each item were averaged to create a composite score representing conversational skills. Internal consistency $(\alpha=.93)$ and inter-rater reliability $(\mathrm{ICC}=.91)$ of the composite score were adequate.

\section{Results}

Descriptive statistics and correlations among all study variable are presented in Table 1. All variables were normally distributed except peer rejection, peer victimization, and parental prosocial advice, which were somewhat skewed toward lower values. Logarithmic transformations of skewed variables were calculated, and results from the original analyses and transformed analyses were nearly identical; thus to enhance interpretability of findings, we present the findings of the original analyses.

Global and context-specific social anxiety were significantly correlated. Peer rejection and peer victimization were positively correlated and peer rejection was associated with lower levels of observed social skill. The three peer-related parenting measures (cognitive framing, prosocial advice, facilitation) were not significantly correlated. Facilitation was associated with more social skills and lower peer rejection. Finally, global social anxiety was significantly and 
positively correlated with both peer rejection and victimization and significantly and negatively correlated with parental facilitation. Context-specific anxiety was associated with lower cognitive framing and prosocial advice.

Plan of Main Analyses

Regression analyses were conducted in AMOS (Arbuckle, 2012) to take advantage of full information maximum likelihood (FIML) estimation to handle missing data. To examine the concurrent links between negative peer experiences and social anxiety, separate models were fit for global and context-specific social anxiety. Each model included two steps. In Step 1, gender, SES, race, and social skills were entered as controls. In Step 2, peer rejection and peer victimization were added. No significant associations were found among control variables and the outcomes.

\section{Predicting Social Anxiety from Peer Problems}

As shown in Table 2, peer rejection was associated with higher levels of both contextspecific social anxiety $(\beta=.33, p<.05)$ and (marginally) global social anxiety $(\beta=.24, p=.06)$, controlling for demographic factors and social skills. In total, $17.4 \%$ of variance in global social anxiety and $8 \%$ of variance in context-specific social anxiety was explained. To examine whether the relations among peer rejection, peer victimization, and social anxiety differed for boys and girls, we tested gender as a moderator of those associations. Young adolescent gender did not moderate associations linking negative peer experiences with social anxiety (Table 2).

\section{Predicting Social Anxiety from Peer-Related Parenting}

Separate models for peer-related parenting were fit for each of the two young adolescent social anxiety outcomes (global and context-specific social anxiety). Each model also included two steps. In Step 1, gender, SES, race and social skills were entered as controls. In Step 2, 
observed parental social coaching variables (cognitive framing and behavioral advice) and parent-reported parental facilitation were added. Similarly, no significant associations were found among control variables and the outcomes.

Global social anxiety. Consistent with expectations, parental facilitation was associated with lower levels of global social anxiety, controlling for demographic factors and social skills. Neither cognitive framing nor behavioral advice was associated with child-reported global social anxiety net of the controls and parental facilitation. In total, $8.8 \%$ of variance in global social anxiety was explained.

Context-specific social anxiety. As expected, parental cognitive framing and behavioral advice were significant, additive predictors of context-specific social anxiety, controlling for demographic factors and social skills $(\beta=-.25, \mathrm{p}<.05 ; \beta=-.26, \mathrm{p}<.05$, respectively). Parental facilitation was not associated with context-specific social anxiety net of controls and parental framing and advice. In sum, $16 \%$ of the variance in context-specific social anxiety was explained.

\section{Predicting Social Anxiety from Peer Problems and Peer-Related Parenting}

The bottom portion of Table 2 summarizes a series of regression analyses in which the additive model of peer problems and peer-related parenting as predictors of social anxiety was tested. The parent and peer predictors in these analyses were those variables that were significantly associated with social anxiety in the preceding analyses. As noted earlier, peer rejection and parental facilitation were marginally significant or significant predictors of selfreported global social anxiety, and peer rejection, observed framing, and behavioral advice were significant predictors of context-specific social anxiety. 
Peer rejection was associated with higher global social anxiety after controlling parental facilitation $(\beta=.29, \mathrm{p}<.05)$ and other study controls. $17.8 \%$ of the variance in global social anxiety was explained. In other words, there were no additive effects for peer problems and parenting in the prediction of global social anxiety. Such additive effects were found for contextspecific social anxiety, however. Context-specific social anxiety was concurrently related to higher levels of peer rejection, lower observed benign framing, and lower observed prosocial advice $(\beta=.24, \beta=-.23, \beta=-.30$, respectively, all $p s<.05)$. A total of $22.2 \%$ of the variance in context-specific social anxiety was explained. Thus, poor quality peer relationships and poorquality parental coaching were independently associated with context-specific social anxiety.

\section{Discussion}

Early adolescence is an important developmental period for the study of social anxiety, due to its growing prevalence and the significant concurrent and long-term maladjustment associated with it (Beidel \& Turner, 2007; Morris, 2001). The present study examined whether peer relationship difficulties and parental social coaching/facilitating were linked with social anxiety, and whether those peer experiences and parenting strategies had additive effects on social anxiety among young adolescents. To test for generality vs. contextual specificity, social anxiety was assessed via adolescent questionnaire-based reports of global anxiety and social anxiety reported in a simulated peer stress situation. An effort was made to ensure methodological/informant independence when possible, with measures of peer relationship difficulties and parental facilitation drawn from parent report, and measures of parental framing and advice giving derived from observation of parental social coaching in the context of an ecologically-relevant, lab-based parent-adolescent discussion about negative peer evaluation. Social skill, a control variable in the present study, also was measured through observers' coding 
in a separate lab-based peer stress context. Thus, the present study minimized informant overlap and therefore provides a conservative test of study hypotheses.

Overall, findings revealed that both peer-related parenting and negative peer experiences were associated with young adolescents' concurrent social anxiety. More specifically with respect to peer problems, higher peer rejection was associated with higher levels of both globaland context-specific social anxiety. In terms of parenting, higher parental facilitation was associated with less global social anxiety, and higher observed positive parental cognitive framing and prosocial advice were associated with less context-specific social anxiety. When considered jointly, peer rejection, observed cognitive framing, and observed prosocial advice were additively associated with social anxiety in the lab-based peer evaluation task. Importantly, these significant associations were found even after controlling for observed social skills. Each of these sets of findings will be discussed in the sections that follow.

\section{Links between Peer Problems and Social Anxiety}

At the bivariate level, both peer victimization and rejection were positively associated with global social anxiety. A somewhat different pattern emerged when control variables (including social skill) were taken into account and both peer problems were considered simultaneously. Results showed that peer rejection significantly predicted higher global social anxiety (marginally) and higher context-specific social anxiety controlling for young adolescents' social skills and peer victimization. This finding is consistent with previous studies (e.g., Greco \& Morris, 2005), suggesting that young adolescents who are rejected by peers may feel uncomfortable with social interactions and have more social anxiety than non-rejected adolescents when facing socially challenging situations. It is possible that peer-rejected adolescents have limited opportunities to habituate to social interactions and to develop a sense 
of competence and social skills, thereby increasing their level of social anxiety (Drake \& Ginsburg, 2012). On the other hand, it is also possible that socially anxious young adolescents behave in ways that engender peer rejection. For example, adolescents with social anxiety may be more sensitive to signs of peer disregard and interpret peer behavior as threatening and then react in a negative manner (Bogels et al., 2003; Miers, Blote, Bogels, \& Westenberg, 2008).

It is worth noting that peer rejection and peer victimization have been found to make unique contributions to adolescents' developmental outcomes (Ladd et al., 1997), but few studies have examined them simultaneously as predictors of social anxiety (Flanagan et al., 2008). In the current study, peer rejection was the only significant predictor of context-specific social anxiety. The peer-evaluation challenge was designed specifically to simulate group-level evaluation, which may explain the unique association between peer rejection and feelings of anxiety in this particular context (Silverman \& Ollendick, 2005). This is consistent with the social informationprocessing theory that processing of information about events in particular kinds of situations would be more strongly predictive of behavior in similar situations than of behavior in other kinds of situations (Pettit \& Mize, 2007).

\section{Links between Peer-Related Parenting and Social Anxiety}

Parental cognitive framing and advice giving were associated with lower levels of context-specific social anxiety but were not associated with global social anxiety. An unexpected bivariate finding was that parental prosocial advice was associated with higher levels of peer victimization. This finding might be interpreted in terms of previous research with children in later childhood that suggest parental prosocial advice plays a more remedial function (McDowell, Parke, \& Wang, 2003). From this perspective, children who suffer from negative peer interactions cause parents to increase their level of intervention, including offering more 
advice to compensate children's lower social competence or skills. Regression analyses showed that framing and advice giving were additive predictors of context-specific anxiety, net of social skills and other controls. Thus, young adolescents' reporting the lowest levels of anxiety before and after the peer evaluation period had parents who were observed to engage in more benign cognitive framing and to provide more prosocial advice.

Parental prosocial advice was expected to be negatively associated with adolescent context-specific social anxiety. However, regarding prosocial advice, evidence of its benefits for children's adjustment is somewhat mixed in the literature. In early childhood, parental advice giving has been found to promote skills that enhance children's ability to form relationships with new peers and gain peer acceptance concurrently and longitudinally (Mize \& Pettit, 1997; Vernberg et al., 1993). During the middle childhood and adolescent developmental periods, researchers have suggested that parents may use advice-giving to compensate for their children's lack of social competence. For example, McDowell, Parke, and Wang (2003) and McDowell and Parke (2009) found that a higher quantity and quality of advice-giving was related to lower levels of social competence among children in middle childhood. In contrast to those empirical investigations who report negative effects of advice giving on adolescent adjustment, we reasoned that young adolescents who received clear and specific prosocial advice from their parents may gradually broaden their vision of social strategies, build confidence, and feel more comfortable when facing challenging social situations. However, one need for caution is that we studied both global and context-specific social anxiety, and only context-specific social anxiety was significant. It could be concluded that parental prosocial advice is more effective when aimed at a specific situation, in this case, a challenging peer evaluation task. Thus, the current 
study provides some support for the positive effects of prosocial advice on social anxiety in young adolescence.

In addition to the influence of prosocial advice on young adolescents' social anxiety, the influence of parental benign cognitive framing has also been found to predict lower levels of social anxiety. Parents may play a vital role in the development of interpretive bias through direct coaching and modeling of various strategies for coping with emotions (e.g., biased or threat). For example, Crewell and O'Connor (2006) found a positive association between children's and mothers' threat cognitions in response to ambiguous situations. In the current study, parents who used negative or threatening interpretations of socially challenging situations might have exacerbated young adolescents' fears and deepened their threat bias (Pettit, Lansford, Malone, Dodge, \& Bates, 2010). On the other hand, young adolescents who received more benign, nonthreatening parental coaching may be more willing to deal with ambiguous or challenging situations and less likely to feel socially anxious (Hane \& Barriors, 2011; Lau et al., 2013). A word of caution is needed in regard to our selection of outcome variables. Specifically, prosocial coaching and benign framing predicted context-specific, but not global social anxiety. One possible explanation is that parental coaching was observed in the context of a specific peer evaluation scenario, and context-specific social anxiety was also assessed in the context of peer evaluation, rather than across a variety of familiar and unfamiliar social situations. The similar context within which parental coaching and context-specific social anxiety were assessed may explain the different results across context-specific and global measures of social anxiety.

An additional goal of the current study was to examine the links between parental facilitation and social anxiety. The bivariate correlations revealed that more parental facilitation was associated with higher levels of social skill and lower levels of peer rejection and global 
social anxiety (McDowell \& Parke, 2009). In the regression analysis parental facilitation continued to predict lower levels of social anxiety even after controlling for social skills and parental social coaching. Parents' provision of social opportunities for their children has received less study than parental social coaching and this is particularly so for research directly examining parental facilitation and social anxiety. Some research has shown that parental facilitation is associated with positive peer relationships and social competence. For example, McDowell and Parke (2009) found that parental facilitation of extracurricular activities with social interactions predicted children's popularity 1 year later. Similarly, in a study of young adolescents, parents' arrangement of social activities for their adolescent and peers predicted youths' likelihood of good friendship 8 months later (Vernberg et al., 1993). Children who participated in more activities provided by parents may have access to a wider variety of social interactions and potential partners. These experiences may serve as a way of expanding children's repertoire of peer interaction skills and making social situations more comfortable and normal, and thus reduce social anxiety.

Do Peer Problems and Peer-Related Parenting Independently Predict Social Anxiety?

Although both peer problems and peer-related parenting have been linked with adolescents' social anxiety (Criss, Shaw, Moilanen, Hitchings, \& Ingoldsby, 2009; Ladd \& Pettit, 2002), few studies have considered them simultaneously. As discussed in the preceding section, parental coaching (cognitive framing and prosocial advice) predicted context-specific social anxiety, and parental facilitation predicted global social anxiety. Peer rejection likewise predicted both global and context-specific social anxiety. Of interest, therefore, is whether parental coaching/facilitation and peer rejection make unique contributions to social anxiety. For global social anxiety, peer rejection remained significant and parental facilitation became non- 
significant, suggesting a parenting-through-peers path. (Recall that facilitation was negatively related to peer rejection.) Results for context-specific social anxiety were more consistent with an additive (cumulative) perspective: Peer rejection and poor parental coaching (low benign framing and low prosocial advice) were both uniquely associated with higher social anxiety during a challenging social situation in the lab. This finding is consistent with empirical evidence that relationships with parents and peers provide unique socialization and cognitive experiences (Criss et al., 2009; Sentse \& Laird, 2010). For example, Festa and Ginsburg (2011) found that parental anxiety and friendship quality predicted social anxiety symptoms. Additionally, this finding is supported by theoretical evidence. According to the developmental psychopathology perspective, adaptation to one's environment is influenced by multiple interpersonal relationships including parents and peers (Sroufe, 1997).

\section{Limitations and Future Directions}

While the results from the current study advance our knowledge about young adolescents' social anxiety, especially by providing new information about the links between parental social coaching and social anxiety, there were several limitations. Although theory and research support the possible influence of negative peer experiences on social anxiety longitudinally (e.g., Siegel et al., 2009; Storch, Masia-Warner, Crisp, \& Klein, 2005; Vernberg et al., 1992), directional and causal conclusions are precluded by the cross-sectional design of the present study. Some studies find bi-directional links between social anxiety and peer relations (Siegel et al., 2009; Storch et al., 2005; Tillfors et al., 2012; Vernberg et al., 1992). Furthermore, some studies have identified subgroups of socially anxious children with and without peer problems (e.g., Erath, Tu, El-Sheikh, 2012; Flanagan et al., 2008; Gazelle, 2008); the existence of such subgroups might explain modest associations between peer problems and social anxiety. 
In addition, the current study combined overt and relational victimization items into a single peer victimization composite variable, whereas other studies have examined the relation between subtypes of victimization (i.e., overt and relational victimization) and social anxiety (Crick \& Nelson, 2001; Katherine et al., 2012; Storch et al., 2004). In the current study, although we used parent-reported negative experiences and self-reported social anxiety to minimize common informant bias, the optimal way to examine peer experiences is through multiple measures, such as peer nominations as well as self, parent, and teacher reports, to provide a more comprehensive picture of peer experiences (Ladd \& Kochenderfer-Ladd, 2002).

No gender differences were found in the current study. Girls were found to have higher social skills but also higher social anxiety than boys, whereas boys received less parental facilitation for social activities. Previous results reported by Erath and colleagues (2007) indicated that boys experienced higher levels of victimization than girls. Furthermore, gender moderated the relationship between social anxiety and victimization, such that the associations between social anxiety and both peer- and self-reported victimization were stronger for boys than girls. They speculated that their findings may relate to the gender difference in peer cultures (i.e., girls' focus on dyadic relationships, boys' orientation to the larger peer group) that emerges in early adolescence (Erath et al., 2007). That was not the case in the current study. Further, context-specific social anxiety in the current study was measured in the context of a conversation between a young adolescent and adult research assistant. Social anxiety levels may have differed in the context of a peer (rather than adult) interaction, and thus future research should examine parent and peer predictors of social anxiety in a peer interaction situation.

\section{Conclusion}


Despite the limitations noted above, the present study helps elucidate the roles of peerrelated parenting (social coaching and facilitation) and peer relationship experiences in young adolescents' social anxiety. Peer rejection and victimization predicted more social anxiety among young adolescents. When parents provided prosocial advice, interpreted social situations as more benign and nonthreatening, and facilitated more peer activities, young adolescents reported less anxiety when facing a challenging social situation. These findings suggest that interventions to reduce social anxiety may be enhanced by including parent- and peer-focused components in addition to individual cognitive and behavioral skills training. 


\section{References}

Abaied, J. L. \& Rudolph, K. D. (2011). Maternal influences on youth responses to peer stress. Developmental Psychology, 47, 1776-1785.

Bagwell, C. L., Molina, B. S., Pelham, W. E., \& Hoza, B. (2001). Attention-deficit hyperactivity disorder and problems in peer relations: predictions from childhood to adolescence. Journal of the American Academy of Child \& Adolescent Psychiatry, 40, 1285-1292.

Beidel, D. C., \& Turner, S. M. (2007). Shy children, phobic adults: Nature and treatment of social phobia. Washington, D.C: American Psychological Association.

Beidel, D. C., Turner, S. M., \& Morris, T. L. (1999). Psychopathology of childhood social phobia. Journal of the American Academy of Child \& Adolescent Psychiatry, 38, 643650.

Beidel, D. C., Turner, S. M., \& Morris, T. L. (2000). Behavioral treatment of childhood social phobia. Journal of Consulting and Clinical Psychology, 68, 1072-1080.

Biggs, B. K., Vernberg, E. M., \& Wu, Y. P. (2012). Social anxiety and adolescents' friendships: The role of social withdrawal. Journal of Early Adolescence, 32, 802-823.

Bukowski, W. M., Sippola, L., Hoza, B., \& Newcomb, A. F. (2000). Pages from a sociometric notebook: An analysis of nomination and rating scale measures of acceptance, rejection, and social preference. In A. N. Cillessen, W. M. Bukowski, A. N. Cillessen, W. M. Bukowski (Eds.), Recent advances in the measurement of acceptance and rejection in the peer system (pp. 11-26). San Francisco, CA, US: Jossey-Bass.

Coie, J. D., \& Dodge, K. A. (1988). Multiple sources of data on social behavior and social status in the school: A cross-age comparison. Child Development, 59, 815-829. 
Cole, D. A., Maxwell, M. A., Dukewich, T. L., \& Yosick, R. (2010). Targeted peer victimization and the construction of positive and negative self-cognitions: Connections to depressive symptoms in children. Journal of Clinical Child \& Adolescent Psychology, 39, 421-435.

Creswell, C., \& O'Connor, T. G. (2006). Anxious cognitions in children: An exploration of associations and mediators. British Journal of Developmental Psychology, 24, 761-766.

Criss, M. M., Pettit, G. S., Bates, J. E., Dodge, K. A., \& Lapp, A. L. (2002). Family adversity, positive peer relationships, and children's externalizing behavior: A longitudinal perspective on risk and resilience. Child Development, 73, 1220-1237.

Criss, M. M., Shaw, D. S., Moilanen, K. L., Hitchings, J. E., \& Ingoldsby, E. M. (2009). Family, neighborhood, and peer characteristics as predictors of child adjustment: A longitudinal analysis of additive and mediation models. Social Development, 18, 511-535

Dodge, K. A., \& Somberg, D. R. (1987). Hostile attributional biases among aggressive boys are exacerbated under conditions of threats to the self. Child Development, 58, 213-224.

Drake, K. L., \& Ginsburg, G. S. (2012). Family factors in the development, treatment, and prevention of childhood anxiety disorders. Clinical Child and Family Psychology Review, $15,144-162$

Duchesne, S., Ratelle, C. F., \& Roy, A. (2012). Worries about the middle school transition and subsequent adjustment: The role of classroom goal structure. Journal of Early Adolescence, 32, 681-710.

Erath, S. A., Flanagan, K. S., \& Bierman, K. L. (2007). Social anxiety and peer relations in early adolescence: Behavioral and cognitive factors. Journal of Abnormal Child Psychology, 35, 405-416. 
Erath, S. A., Tu, K. M., \& El-Sheikh, M. (2012). Socially anxious and peer-victimized preadolescents: "Doubly primed" for distress? Journal of Abnormal Child Psychology, 40, $837-848$.

Fanti, K. A., \& Henrich, C. C. (2010). Trajectories of pure and co-occurring internalizing and externalizing problems from age 2 to age 12: Findings from the National Institute of Child Health and Human Development Study of Early Child Care. Developmental Psychology, 46, 1159-1175.

Ferrell, C., Beidel, D., \& Turner, S. (2004). Assessment and treatment of socially phobic children: A cross-cultural comparison. Journal of Clinical Child and Adolescent Psychology, 33, 260-268

Festa, C. C., \& Ginsburg, G. S. (2011). Parental and peer predictors of social anxiety in youth. Child Psychiatry and Human Development, 42, 291-306.

Flanagan, K. S., Erath, S. A., \& Bierman, K. L. (2008). Unique associations between peer relations and social anxiety in early adolescence. Journal of Clinical Child and Adolescent Psychology, 37, 759-769.

Gazelle, H. (2008). Behavioral profiles of anxious solitary children and heterogeneity in peer relations. Developmental Psychology, 44, 1604-1624.

Goodman, R., Meltzer, H., \& Bailey, V. (1998). The Strengths and Difficulties Questionnaire: A pilot study on the validity of the self-report version. European Child \& Adolescent Psychiatry, 7, 125-130.

Greco, L. A., \& Morris, T. L. (2005). Factors influencing the link between social anxiety and peer acceptance: Contributions of social skills and close friendships during middle childhood. Behavior Therapy, 36, 197-205. 
Gregson, K.D., Erath, S.A., Pettit, G.S., \& Tu, K.M. (in press). Are they listening? Parental social coaching and parenting emotional climate predict adolescent receptivity. Journal of Research on Adolescence, doi:10.1111/jora.12222

Gren-Landell, M., Aho, N., Andersson, G., \& Svedin, C. G. (2011). Social anxiety disorder and victimization in a community sample of adolescents. Journal of Adolescence, 34, 569577.

Hane, A. A., \& Barrios, E. S. (2011). Mother and child interpretations of threat in ambiguous situations: Relations with child anxiety and autonomic responding. Journal of Family Psychology, 25, 644-652.

Holt, M. K., Kaufman Kantor, G., \& Finkelhor, D. (2008). Parent/child concordance about bullying involvement and family characteristics related to bullying and peer victimization. Journal of School Violence, 8, 42-63.

Kingery, J. N., Erdley, C. A., Marshall, K. C., Whitaker, K. G., \& Reuter, T. R. (2010). Peer experiences of anxious and socially withdrawn youth: An integrative review of the developmental and clinical literature. Clinical Child and Family Psychology Review, 13, 91-128.

La Greca, A. M., \& Harrison, H. M. (2005). Adolescent peer relations, friendships, and romantic relationships: Do they predict social anxiety and depression? Journal of Clinical Child and Adolescent Psychology, 34, 49-61.

La Greca, A. M., \& Lopez, N. (1998). Social anxiety among adolescents: Linkages with peer relations and friendships. Journal of Abnormal Child Psychology, 26, 83-94.

Ladd, G. W. (1999). Peer relationships and social competence during early and middle childhood. Annual Review of Psychology, 50, 333-359. 
Ladd, G.W., (2005). Children's peer relationships and social competence: A century of progress. New Haven, CT: Yale University Press.

Ladd, G. W., \& Kochenderfer-Ladd, B. (2002). Identifying victims of peer aggression from early to middle childhood: analysis of cross informant data for concordance, estimation of relational adjustment, prevalence of victimization, and characteristics of identified victims. Psychological Assessment, 14, 74-96.

Ladd, G. W., \& Pettit, G. S. (2002). Parenting and the development of children's peer relationships. In M. H. Bornstein, M. H. Bornstein (Eds.), Handbook of parenting: Vol. 5: Practical issues in parenting (2nd ed.) (pp. 269-309). Mahwah, NJ, US: Lawrence Erlbaum Associates Publishers.

Ladd, G. W., Kochenderfer, B. J., \& Coleman, C. C. (1997). Classroom peer acceptance, friendship, and victimization: Distinct relation systems that contribute uniquely to children's school adjustment? Child Development, 68, 1181-1197.

Lau, J. Y., Pettit, E., \& Creswell, C. (2013). Reducing children's social anxiety symptoms: Exploring a novel parent-administered cognitive bias modification training intervention. Behaviour Research and Therapy, 51, 333-337.

Leary, M. R., \& Kowalski, R. M. (1997). Social anxiety. New York, NY, US: Guilford Press

Mathews, A., \& MacLeod, C. (2005). Cognitive vulnerability to emotional disorders. Annual Review of Clinical Psychology, 1, 167-195.

McDowell, D. J., \& Parke, R. D. (2009). Parental correlates of children's peer relations: An empirical test of a tripartite model. Developmental Psychology, 45, 224. 
McDowell, D. J., Parke, R. D., \& Wang, S. J. (2003). Differences between mothers' and fathers' advice-giving style and content: Relations with social competence and psychological functioning behavior in middle childhood. Merrill-Palmer Quarterly, 49, 55-76.

McLeod, B. D., Wood, J. J., \& Weisz, J. R. (2007). Examining the association between parenting and childhood anxiety: A meta-analysis. Clinical Psychology Review, 27, 155-172.

Miers, A. C., Blote, A. W., Bogels, S. M., \& Westenberg, P. M. (2008). Interpretation bias and social anxiety in adolescents. Journal of Anxiety Disorders, 22, 1462-1471.

Mize, J., \& Pettit, G. S. (1997). Mothers' social coaching, mother-child relationship style, and children's peer competence: Is the medium the message? Child Development, 68, 312323.

Morris, T. L. (2001). Social phobia. In M.W. Vasey \& M. R. Dadds (Eds.). The Developmental Psychopathology of Anxiety. New York: Oxford University Press.

Nansel, T. R., Overpeck, M., Pilla, R. S., Ruan, W. J., Simons-Morton, B., \& Scheidt, P. (2001). Bullying behaviors among US youth: Prevalence and association with psychosocial adjustment. Jama, 285, 2094-2100.

Parker, J. G., Rubin, K. H., Erath, S. A., Wojslawowicz, J. C., \& Buskirk, A. A. (2006). Peer relationships, child development, and adjustment: A developmental psychopathology perspective. In D. Cicchetti, D. J. Cohen, D. Cicchetti, D. J. Cohen (Eds.), Developmental psychopathology, Vol 1: Theory and method (2nd ed.) (pp. 419-493). Hoboken, NJ, US: John Wiley \& Sons Inc.

Pettit, G. S., Lansford, J. E., Malone, P. S., Dodge, K. A., \& Bates, J. E. (2010). Domain specificity in relationship history, social-information processing, and violent behavior in early adulthood. Journal of Personality and Social Psychology, 98, 190-200. 
Pettit, G. S., \& Mize, J. (2007). Social-cognitive processes in the development of antisocial and violent behavior. In D. J. Flannery, A. T. Vazsonyi, I. D. Waldman, D. J. Flannery, A. T. Vazsonyi, I. D. Waldman (Eds.), The Cambridge handbook of violent behavior and aggression (pp. 322-343). New York, NY, US: Cambridge University Press.

Pettit, G. S., Polaha, J. A., \& Mize, J. (2001). Perceptual and attributional processes in aggression and conduct problems. In J. Hill, B. Maughan, J. Hill, B. Maughan (Eds.), Conduct disorders in childhood and adolescence (pp. 292-319). New York, NY, US: Cambridge University Press.

Poulin, F., Nadeau, K., \& Scaramella, L. V. (2012). The role of parents in young adolescents' competence with peers: An observational study of advice giving and intrusiveness. Merrill-Palmer Quarterly, 58, 437-462.

Reuland, M. M., \& Teachman, B. A. (2014). Interpretation bias modification for youth and their parents: A novel treatment for early adolescent social anxiety. Journal of Anxiety Disorders, 28, 851-864.

Rao, P. A., Beidel, D. C., Turner, S. M., Ammerman, R. T., Crosby, L. E., \& Sallee, F. R. (2007). Social anxiety disorder in childhood and adolescence: Descriptive psychopathology. Behaviour Research and Therapy, 45, 1181-1191.

Rubin, K. H., \& Burgess, K. B. (2001). Social withdrawal and anxiety. In M. W. Vasey, M. R. Dadds, M. W. Vasey, M. R. Dadds (Eds.), The developmental psychopathology of anxiety (pp. 407-434). New York, NY, US: Oxford University Press.

Schwartz, D., Farver, J., Chang, L., \& Lee-Shin, Y. (2002). Victimization in South Korean children's peer groups. Journal of Abnormal Child Psychology, 30, 113-125. 
Sentse, M., \& Laird, R. D. (2010). Parent-child relationships and dyadic friendship experiences as predictors of behavior problems in early adolescence. Journal of Clinical Child and Adolescent Psychology, 39, 873-884

Siegel, R. S., La Greca, A. M., \& Harrison, H. M. (2009). Peer victimization and social anxiety in adolescents: Prospective and reciprocal relationships. Journal of Youth and Adolescence, 38, 1096-1109.

Silverman, W. K., \& Ollendick, T. H. (2005). Evidence-based assessment of anxiety and its disorders in children and adolescents. Journal of Clinical Child and Adolescent Psychology, 34, 380-411.

Sroufe, A. (1997). Psychopathology as an outcome of development. Development and Psychopathology, 9, 251-268.

Steinberg, L., \& Morris, A. S. (2001). Adolescent development. Journal of Cognitive Education and Psychology, 2, 55-87.

Storch, E. A., \& Ledley, D. R. (2005). Peer victimization and psychosocial adjustment in children: Current knowledge and future directions. Clinical Pediatrics, 44, 29-38.

Storch, E. A., Masia-Warner, C., Crisp, H., \& Klein, R. G. (2005). Peer victimization and social anxiety in adolescence: A prospective study. Aggressive Behavior, 31, 437-452.

Storch, E. A., Nock, M. K., Masia-Warner, C., \& Barlas, M. E. (2003). Peer victimization and social-psychological adjustment in Hispanic and African-American children. Journal of Child and Family Studies, 12, 439-452.

Tillfors, M., Persson, S., Willén, M., \& Burk, W. J. (2012). Prospective links between social anxiety and adolescent peer relations. Journal of Adolescence, 35, 1255-1263. 
Vernberg, E. M., Abwender, D. A., Ewell, K. K., \& Beery, S. H. (1992). Social anxiety and peer relationships in early adolescence: A prospective analysis. Journal of Clinical Child Psychology, 21, 189-196.

Vernberg, E. M., Beery, S. H., Ewell, K. K., \& Absender, D. A. (1993). Parents' use of friendship facilitation strategies and the formation of friendships in early adolescence: A prospective study. Journal of Family Psychology, 7, 356-369.

Wang, J., Iannotti, R. J., \& Nansel, T. R. (2009). School bullying among adolescents in the United States: Physical, verbal, relational, and cyber. Journal of Adolescent Health, 45, 368-375.

Westenberg, P. M., Gullone, E., Bokhorst, C. L., Heyne, D. A., \& King, N. J. (2007). Social evaluation fear in childhood and adolescence: Normative developmental course and continuity of individual differences. British Journal of Developmental Psychology, 25, 471-483.

Williams, K. R., \& Guerra, N. G. (2007). Prevalence and predictors of internet bullying. Journal of Adolescent Health, 41, S14-S21. 
Table 1

Correlations and descriptive statistics.

\begin{tabular}{|c|c|c|c|c|c|c|c|c|c|c|c|}
\hline & 1 & 2 & 3 & 4 & 5 & 6 & 7 & 8 & 9 & 10 & 11 \\
\hline 1. Gender & - & & & & & & & & & & \\
\hline 2. Race/ethnicity & .01 & - & & & & & & & & & \\
\hline 3. Income & $-.24 *$ & $-.58 * * *$ & - & & & & & & & & \\
\hline 4. Social Skills & .02 & -.17 & .17 & - & & & & & & & \\
\hline 5. PR peer victim & .08 & -.05 & -.16 & -.01 & - & & & & & & \\
\hline 6. PR peer reject & .02 & -.12 & -.18 & $-.25^{*}$ & $.59 * * *$ & - & & & & & \\
\hline 7. Cognitive framing & .10 & .01 & -.07 & .17 & .06 & -.15 & - & & & & \\
\hline 8. Prosocial advice & -.12 & -.22 & .08 & .21 & $.35 * *$ & .16 & .14 & - & & & \\
\hline 9. Facilitation & $.27^{*}$ & $-.27 *$ & $.27 *$ & $.36 * *$ & -.08 & $-.36 * *$ & .04 & .04 & - & & \\
\hline 10. Global SA & .02 & .10 & -.08 & -.18 & $.27 *$ & $.31 * *$ & -.04 & -.09 & $-.27 *$ & - & \\
\hline 11. Lab SA & -.02 & .00 & .02 & .08 & -.04 & .14 & $-.27^{*}$ & $-.24 *$ & .11 & $.31 * *$ & - \\
\hline$N$ & 80 & 80 & 78 & 79 & 80 & 80 & 80 & 80 & 80 & 80 & 80 \\
\hline \multirow[t]{2}{*}{ Mean $(S D) / \%$} & 45 & 55 & 3.83 & 3.38 & .75 & .77 & 3.39 & 1.53 & 2.54 & 2.29 & 2.96 \\
\hline & & & $(1.59)$ & $(1.04)$ & $(.80)$ & $(.59)$ & $(.98)$ & $(1.12)$ & $(.78)$ & $(.86)$ & $(1.14)$ \\
\hline
\end{tabular}

Note. Gender was coded as $1=$ Female and $0=$ Male; Race/ethnicity was coded $1=$ African American and $0=$ others, SA $=$ social anxiety, $\mathrm{PR}=$ parent-reported; $* p<.05 ; * * p<.01 ; * * * p<.001$ 
Table 2

Predicting young adolescent self-reported global and context-specific social anxiety from peer problems and peer-related parenting.

\begin{tabular}{|c|c|c|c|c|}
\hline & \multicolumn{2}{|c|}{ Global SA } & \multicolumn{2}{|c|}{ Context-specific SA } \\
\hline & $\mathrm{B}(\mathrm{SE})$ & $\beta$ & $\mathrm{B}(\mathrm{SE})$ & $\beta$ \\
\hline \multicolumn{5}{|c|}{ Main effects of peer variables } \\
\hline PR peer rejection & $.36(.20)$ & $.24 \sim$ & $.64(.27)$ & $.33^{*}$ \\
\hline PR peer victimization & $.16(.14)$ & .15 & $-.31(.19)$ & -.22 \\
\hline \multicolumn{5}{|l|}{ Interaction with Gender } \\
\hline Gender $\mathrm{X}$ rejection & $.19(.38)$ & .12 & $-.01(.52)$ & -.01 \\
\hline Gender $\mathrm{X}$ victim & $-.29(.38)$ & -.23 & $-.58(.40)$ & -.35 \\
\hline \multicolumn{5}{|c|}{ Main effects of parenting variables } \\
\hline OC Framing & $-.03(.10)$ & -.03 & $-.29(.12)$ & $-.25^{*}$ \\
\hline OC advice & $-.04(.09)$ & -.05 & $-.27(.11)$ & $-.26^{*}$ \\
\hline PR Facilitation & $-.30(.14)$ & $-.27 *$ & $.16(.18)$ & .11 \\
\hline \multicolumn{5}{|l|}{ Interaction with Gender } \\
\hline Gender $\mathrm{X}$ framing & $.15(.22)$ & .31 & $-.01(.25)$ & -.02 \\
\hline Gender $\mathrm{X}$ advice & $-.01(.24)$ & .01 & $.27(.26)$ & .22 \\
\hline Gender $\mathrm{X}$ facilitation & $.02(.28)$ & .03 & $.16(.31)$ & .20 \\
\hline \multicolumn{5}{|c|}{ Additive effects of peer and parenting variables } \\
\hline PR peer rejection & $.42(.17)$ & $.29 *$ & $.46(.20)$ & $.24 *$ \\
\hline PR Facilitation & $-.18(.14)$ & -.16 & & \\
\hline OC framing & & & $-.27(.12)$ & $-.23 *$ \\
\hline OC advice & & & $-.31(.10)$ & $-.30 * *$ \\
\hline
\end{tabular}

Note. Gender, race, income, and social skills controlled in all regression analysis; $\mathrm{SA}=$ social anxiety, $\mathrm{PR}=$ parent-reported, $\mathrm{OC}=$ observed coaching; $\sim p<.10 ; * p<.05 ; * * p<.01$ 